УДК 536.423+532.528

\title{
ДОСЛІДЖЕННЯ ВПЛИВУ МЕХАНІЗМІВ ДИСКРЕТНО-ІМПУЛЬСНОГО ВВЕДЕННЯ ЕНЕРГІЇ НА ВОДНЕВИЙ ПОКАЗНИК ВОДНИХ СИСТЕМ
}

Долінський А.А., академік НАН України, Шурчкова Ю.А., докт. техн. наук, Дубовкіна I.О., докторант, Коник А.В., канд. техн. наук

Інститут технічної теплофізики НАН України, вул. Желябова, 2а, м. Київ, 03680, Украӥна

У статті представлено дослідження активації водних систем методом ДІВЕ. Наведено результати експериментальних досліджень впливу механізмів ДІВЕ: миттєвого скидання тиску (вакуумування), адіабатичного закипання і високочастотних гідродинамічних коливань на водневий показник різних типів води. Встановлено степінь підвищення водневого показника i його стійкість в часі.
В статье представлены исследования активации водных систем методом ДИВЭ. Приведены результаты экспериментальных исследований влияния механизмов ДИВЭ: мгновенного сброса давления (вакуумирование), адиабатического вскипания и высокочастотных гидродинамических колебаний на водородный показатель разных типов воды. Определена степень повышения водородного показателя, и его стойкость во времени.
Researches of activating of the water systems the method of DPIE are presented in the article. Results over of experimental researches of influence of mechanisms of DPIE are brought: instantaneous depressurization (vacuumizing), adiabatic boiling up and highfrequency hydrodynamic vibrations on the ph-value of different types of water. The degree of increase of ph-value and its stability throughout time is set.

Бібл. 8, рис. 4.

Ключові слова: дискретно-імпульсне введення енергії, скидання тиску, адіабатичне закипання, високочастотні гідродинамічні коливання, вода, водні системи.

ВЧГДК - високочастотні гідродинамічні коливання;

ДІВЕ - дискретно-імпульсне введення енергії; $\mathrm{EBC}$ - експериментальний вакуумний стенд;

Стрімкий розвиток нанотехнологій викликає необхідність вивчення та дослідження процесів, що протікають на мікро- та нанорівнях: гідратація, активація та структуроутворення. Використання безреагентних методів, що дозволяють інтенсифікувати ряд технологічних процесів потребує особливої уваги, оскільки від них залежить підвищення якості готового продукту та зниження енергоспоживання.

3 метою прискорення хімічних, фазових та інших перетворень доцільно застосовувати метод активації рідких середовищ (водних систем). Дослідження по активації води та водних систем в електричному і магнітному полі дозволили визначити суттєві можливості в області інтенсифікації процесів: дифузії, екстрагування, кристалізації, випарювання, абсорбції, ректифікації та ін. Використання в промисловості різних методів активації води, водних систем та водних
РПА - роторно-пульсаційний апарат; $\mathrm{pH}$ - водневий показник;

ТВО - термовакуумна обробка.

розчинів викликає значний інтерес i набуває суттєвого значення. Особливого наукового і практичного значення набувають питання вибору та оцінки методів активації, дослідження механізму фізичних явищ при активації і узагальнення отриманих експериментальних даних.

Активацію води та водних систем можна проводити різними способами: кавітаційно-кумулятивним впливом та ударними хвилями, механічною дезінтеграцією, впливом електричного чи магнітного полів, дегазацією, талою водою, швидко охолодженою кип'яченою водою, використанням електрогідроефекту, проникаючим випромінюванням і т.п.

Окрім сил хімічної взаємодії, що призводить до утворення валентних хімічних зв'язків між атомами (утворення молекул) існують додаткові сили взаємодії між молекулами. Енергія таких міжмолекулярних чи ван-дер-ваальсових взає- 
модій на кілька порядків менша енергії ковалентного зв'язку. Наявність таких взаємодій принципово не змінює властивостей молекул. Між цими двома крайніми випадками існують взаємодії, проміжні за енергією, що призводять до утворення ассоціатів. До числа таких ассоціативних взаємодій належить водневий зв'язок [1]. Утворення водневого зв'язку відбувається при взаємодії протонодонора (кислоти Бренстеда, електроноакцептора) 3 протоноакцептором (основою, електронодонором).

Вода $є$ унікальним розчинником. За фізичними характеристиками вода добре сольватує як недисоційовані молекули, так і вільні іони [2]. Крім того молекули води здатні до автопротолізу - передачі протона між молекулами однієї і тієї ж речовини. При утворенні водневих зв'язків виділяється теплота - термохімічна міра енергії Н-зв'язку.

В результаті проведених досліджень термодинамічних властивостей, світлорозсіювання і поглинання ультразвуку було встановлено, що активовані водні системи мають формальну схожість 3 кристалічними бінарними розплавами і можуть переходити із стану 3 невпорядкованою структурою в стан 3 упорядкованою структурою - в систему, в якій існує неперервна тривимірна сітка водневих зв'язків [3].

Загальним, що виявляється при експериментальному дослідженні різних методів активації води та водних систем $є$ збільшення концентрації водневих іонів, а відповідно, і електричної провідності, при цьому стійкість активованої води складає від 4...5 діб до 60..70 хв., залежно від методу. У зв'язку з цим відбувається пошук нових методів, що можуть забезпечити стійкість активованих водних систем в часі.

Метою роботи $є$ дослідження зміни водневого показника $\mathrm{pH}$ активованої води та водних систем безреагентним впливом - методом дискретно-імпульсного введення енергії, а саме використанням високочастотних гідродинамічних коливань, та скиданням тиску, що супроводжується адіабатичним закипанням.

В Інституті технічної теплофізики НАН України проводяться дослідження властивостей води та водних систем, активованих із застосуванням методу ДІВЕ: скиданням тиску в об'ємі, при витіканні через насадку, та обробкою високочастотними гідродинамічними коливаннями. Для досліджень в ІТТФ НАН України створено та застосовується експериментально-дослідне обладнання: експериментальний вакуумний стенд [4], термовакуумна обробка [5] і роторно-пульсаційний апарат [6].

ЕВС дозволяє проводити дослідження скидання тиску над поверхнею рідини в об'ємі та при витіканні через насадку. Вибір параметрів досліджень базується на основних умовах протікання процесу адіабатного закипання: $T_{\text {води }}>T_{\text {кип }}(P)$, оскільки, вода 3 температурою $60{ }^{\circ} \mathrm{C}$ закипає при тиску 20 кПа, то для досліджень було обрано діапазон скидання тиску від 98,1 кПа до $10 . .20$ кПа і в діапазоні температури від $20{ }^{\circ} \mathrm{C}$ до $100^{\circ} \mathrm{C}$.

Дослідження скидання тиску проводились в об'ємі, для цього дослідний зразок розміщували у вакуумній камері, де відбувалось скидання тиску до заданої величини, після чого зразок витримували протягом 1 хвилини. Дослідження процесу витікання проводилось при пропусканні рідини через насадку у вакуумну камеру. Для досліджень зміни водневого показника рН активованих водних систем в якості модельних середовищ було обрано артезіанську, водопровідну і дистильовану воду. Результати дослідження процесу скидання тиску представлено на рис. 1 і на рис. 2 скидання тиску, що супроводжується адіабатичним закипанням, величина перегріву складає $\Delta T=15$.

Представлені результати досліджень впливу скидання тиску на рН води підтверджують, що незалежно від типу води суттєве підвищення водневого показника (до 7,3 \%) спостерігається при організації процесу дворазового витікання через насадку (рис. 1). Результати досліджень скидання тиску, що супроводжується адіабатичним закипанням вказують на підвищення водневого показника від 12 до $20 \%$ (рис. 2). Максимальне підвищення $\mathrm{pH}$ води відбувається при скиданні тиску в об'ємі, де адіабатичне закипання середовища триває 1 хвилину. Необхідно зазначити, що $\mathrm{pH}$ отриманих зразків зберігається протягом 6 місяців.

Для дослідження впливу багаторазового скидання тиску на водневий показник води було ви- 


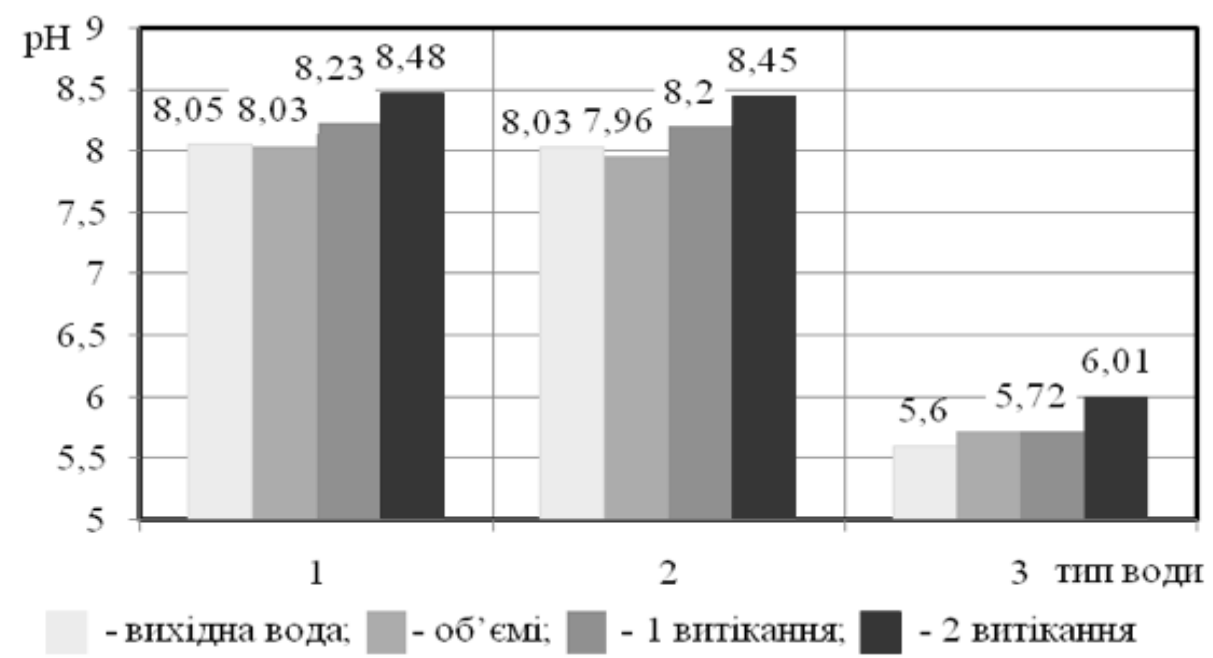

Рис. 1. Зміна водневого показника в залежності від способу організацї̈ процесу скидання тиску $\left(P=10\right.$ кПа, $\left.T=20^{\circ} \mathrm{C}\right): 1$ - водопровідна вода, 2 - артезіанська вода, 3 -дистильована вода.

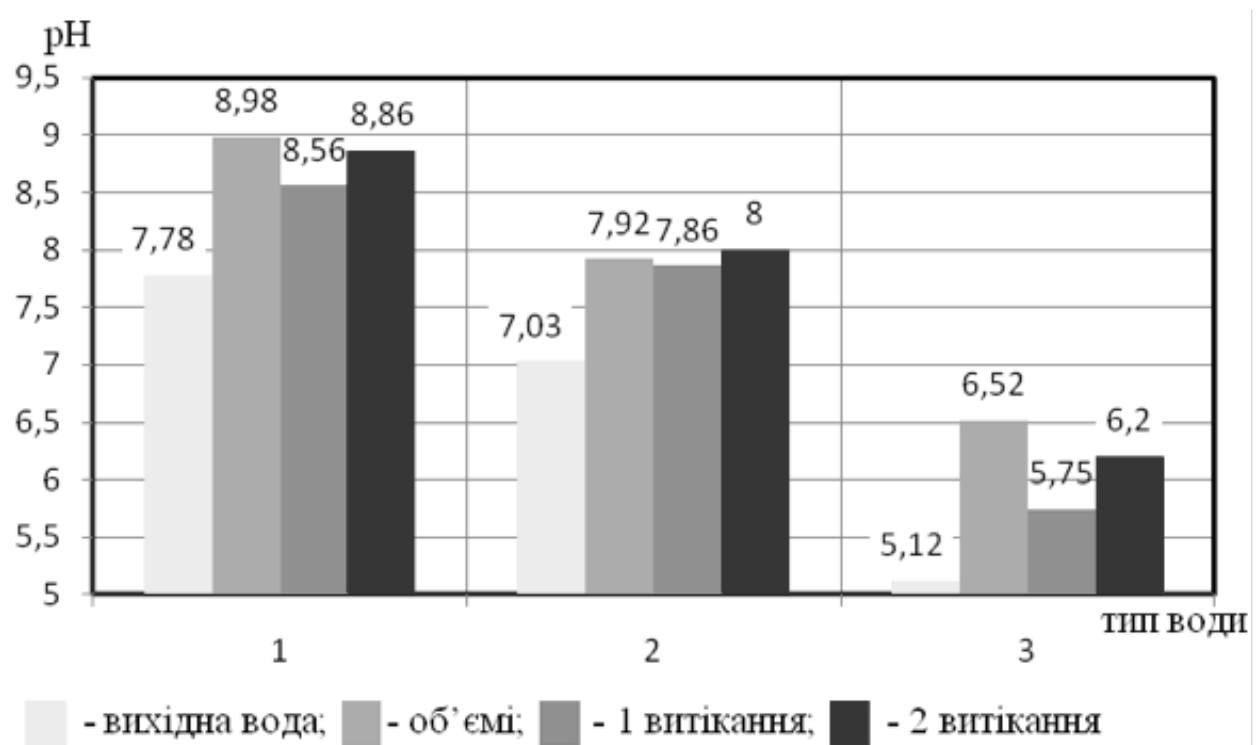

Рис. 2. Зміна водневого показника в залежності від способу організації процесу скидання тиску $\left(P=10\right.$ кПа, $\left.\Delta T=15^{\circ} \mathrm{C}\right): 1$ - водопровідна вода, 2 - артезіанська вода, 3 - дистильована вода.

користано апарат адіабатичного закипання [5], що є основою термовакуумної технології. ТВО це низка взаємозалежних процесів адіабатного закипання, конденсації, нагрівання, випаровування, охолодження, що протікають в імпульсному режимі зміни тиску і температури. Дослідження проводились при скиданні тиску від 98,1 кПа до 5 кПа в діапазоні температур від $10{ }^{\circ} \mathrm{C}$ до $95{ }^{\circ} \mathrm{C}$. Зразки відбирались після кожного процесу при температурі $40,80,95^{\circ} \mathrm{C}$, щоб встановити степінь впливу температури пере- гріву на $\mathrm{pH}$ модельного середовища. Необхідно зауважити, що процес адіабатного закипання відбувається при витіканні через насадку, а в якості модельного середовища було використано артезіанську воду.

3 рис. 3 видно, що значне підвищення водневого показника спостерігається після етапу нагрівання. Необхідно зазначити, що чим вище температура перегріву $\Delta T$, тим вище значення $\mathrm{pH}$, що свідчить про суттєвий вплив адіабатичного закипання, окрім цього, процес супровод- 


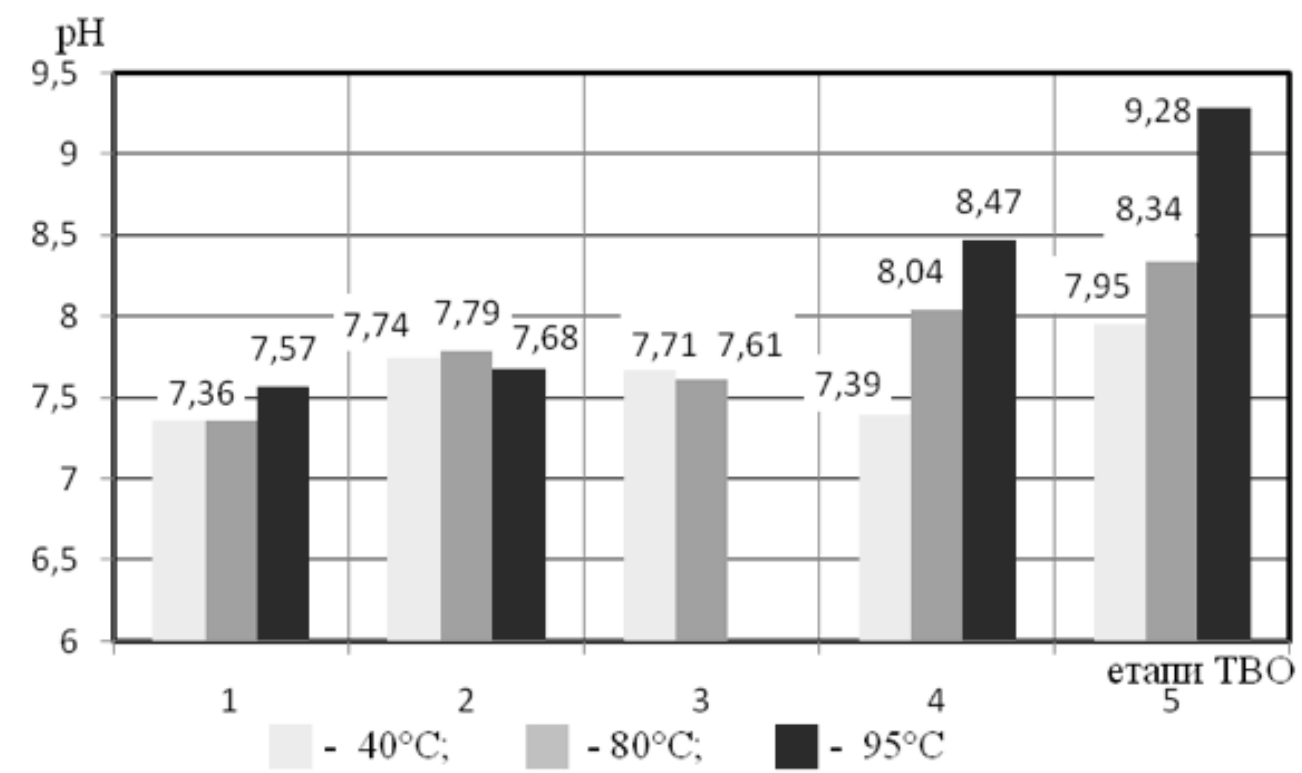

Рис. 3. Зміна водневого показника води на різних етапах ТВО: 1 - вихідна вода, 2 - після конденсування, 3 - після нагрівання, 4 - після випаровування (закипання), 5 - після охолодження.

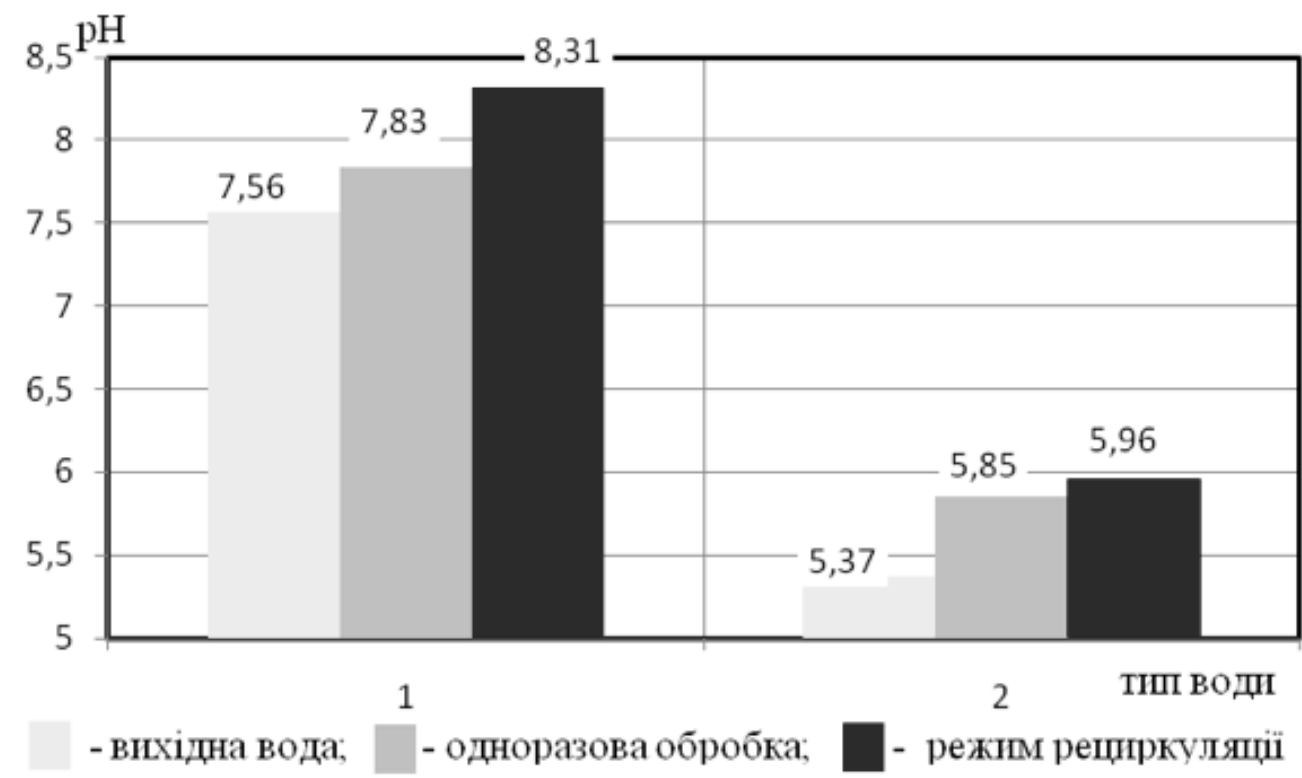

Рис. 4. Зміна водневого показника води в залежності від степені обробки та типу води: 1 - артезіанська вода, 2 - дистильована вода.

жується глибокою дегазацією при $\Delta T=15^{\circ} \mathrm{C}$ вміст повітря складає $0,7 \ldots 0,8 \mathrm{~cm}^{3} /$ л, при $\Delta T=30{ }^{\circ} \mathrm{C}$ близько $0,1 \ldots 0,15 \mathrm{~cm}^{3} /$ л.

Дослідження впливу ВЧГДК на $\mathrm{pH}$ води проводились на роторно-пульсаційному апараті, основним елементом якого $є$ робочий вузол, що складається 3 системи «ротор-статор-ротор» [6]. На роторах та статорі розташовані щілинні зазори при перекритті яких відбувається різка зміна тиску від 0,2 МПа до 0,001 МПа і величина падіння тиску за секунду складає $d P / d \tau=0,6$ ГПа/с. РПА $з$ величиною зазору 
100 мкм в системі «ротор-статор-ротор» за розрахунковими даними приведеними в [7], має швидкість зсуву до $2,35 \cdot 10^{5} \mathrm{c}^{-1}$ i напруження зсуву до 235,5 Па. Окрім цього розраховано, що елементарний об'єм перебуває в робочому вузлі $69 \cdot 10^{-3}$ с, при цьому кількість коливань, що отримує елементарний об'єм при проходженні через робочий вузол становить $168 \ldots 207$. В якості модельних середовищ було обрано артезіанську і дистильовану воду.

В результаті проведених досліджень (рис. 4), було встановлено, що при одноразовій обробці рН підвищується від 3,5\%, та до 10,9\% в режимі рециркуляції відповідно.

\section{Висновки}

За результатами експериментальних досліджень встановлено вплив адіабатичного закипання i високочастотних гідродинамічних коливань на зміну водневого показника модельних середовищ.

Отримані результати доводять доцільність застосування методу дискретно-імпульсного введення енергії для активації водних систем, оскільки відбувається суттєва зміна водневого показника $\mathrm{pH}$ при різних методах впливу, так при миттєвому скиданні тиску до 7,3 \%, при скиданні тиску, що супроводжується адіабатичним закипанням до $20 \%$ на експериментальному вакуумному стенді. Дослідження адіабатичного закипання за термовакуумною обробкою свідчать про підвищення $\mathrm{pH}$ до $16 \%$ в режимі імпульсної зміни тиску і температури та до 10,9 \% в режимі рециркуляції при накладенні високочастотних гідродинамічних коливань.

Експериментальним шляхом було підтверджено, що отримане підвищення $\mathrm{pH}$ води зберігається протягом тривалого часу, наприклад, після термовакуумної обробки до 18 місяців, після роторно-пульсаційного апарату до 6 місяців.

Експериментальні дані розширюють уявлення про можливість зміни властивостей водних систем за рахунок зміни їх структури, а саме за рахунок утворення сітки водневих зв'язків, застосовуючи безреагентні методи активації та впливу. В результаті обробки можна отримати воду 3 заздалегідь заданими фізичними властивостями, без застосування хімічних речовин та домішок, що є важливим показником при приготуванні пива, соків, алкогольних і безалкогольних напоїв.

\section{ЛІТЕРАТУРА}

1. Москва B.B. Водородная связь в органической химии / Соросовский образовательный журнал - 1999. - № 2. - С. 58 - 64.

2. Дубовкіна I.О. Дослідження властивостей водних систем при обробці методом дискретно-імпульсного введення енергії та перспективи їх використання / Дубовкіна I.O, Шурчкова Ю.О. Третя науково-практична конференція 3 міжнародною участю «Вода в харчовій промисловості»: Збірник матеріалів Третьої науково-практичної конференції. - Одеса: OHAXT, 2012. - $116 \mathrm{c}$.

3. Вукс М.Ф., Шурупова Л.В. Молекулярная физика и биофизика водных систем / Журнал структурной химии. - 1971. - 12, № 4. С. 712 713, С. $730-731$.

4. Шурчкова Ю.А., Сланік А.В. Опис експериментального вакуумного стенду для дослідження процесів миттєвого скидання тиску в об’ємі та при витіканні рідини // Збірник тез доповідей VIII всеукраїнської науковопрактичної конференції студентів, аспірантів і молодих вчених, С. $16-17$.

5. Иваницкий Г.К., Шурчкова Ю.А., Целень Б.Я., Сланик A.B. Сокращение энергетических затрат при обработке воды методом дискретно-импульсного ввода энергии // Зборник тезисов IV Межд. Науч.-практич. Конференции «Современные энергосберигающие тепловые технологии (сушка и термовлажностная обработка материалов). СЕТТ - 2011», - Т.1. - С. 446 -450 .

6. Долинский А.А., Шурчкова Ю.А., Сланик $A . B$. Микроструктура сухого остатка воды при различных способах её обработки // Пром. теплотехника. - 2009. - Т.31, №7. - С. $86-89$.

7. Сланік А.В. Використання механізмів дискретно-імпульсного введення енергії для 
обробки води: дис. на здобуття наук. степеня кандидата технічних наук: 05.14.06 «Технічна теплофізика та промислова теплоенергетика»/ А.В. Сланік. - Київ, 2010. - 190 с.

\section{RESEARCH OF INFLUENCE OF MECHANISMS OF DISCRETE-PULSE INPUT OF EN-ERGY ON A PH-VALUE OF WATER}

\section{Dolinsky A.A., Shurchkova J.O., Dubovkina I.O., Konyk A.V.}

Institute of Engineering Thermophysics of the National Academy of Sciences of Ukraine, vul. Zhelyabova, 2a, Kyiv, 03680, Ukraine

Researches of activating of the water systems the method of descrete-pulse input of energy are presented in the article. Results over of experimental researches of influence of mechanisms of DPIE are brought: instantaneous depressurization (vacuumizing), adiabatic boiling up and high-frequency hydrody-namic vibrations on the $\mathrm{pH}$-value of different types of water: artesian, distilled, tap water. Water with the physical properties set in good time, without application of chemicals and admixtures was received by DPIE method. The degree of increase of $\mathrm{pH}$-value and its stability throughout time is set. It was confirmed by an experimental way that got step $\mathrm{pH}$-value of water kept during great while. References 8, figures 4 .

Key words: discrete-pulse input of energy, depressurization, adiabatic boiling up, high-frequency hydrody-namic vibrations, water, water systems.
8. Долинский А.А., Шурчкова Ю.А. Вода в условии обработки ДИВЭ // Доповіді НАН України - 2013. - №8, - С. 35 - 39.
1. Moskva V.V. Hydrogen bond in organic chemistry / the Sorosovskyy educational magazine - 1999. - № 2. - P. 58 - 64 (Rus.)

2. Dubovkina I.O. Research of properties of the water systems at treatment a method discretely-impulsive introduction of energy and prospect of their use / Dubovkina I.O, Shurchkova Yu.O. Tretya naukovo-praktychna konferentsiya $\mathrm{z}$ mizhnarodnoyu uchastyu «Voda V kharchoviy promyslovosti»: Zbirnyk materialiv Tret'oyi naukovo-praktychnoyi konferentsiyi. Odesa: ONAKhT, 2012. - 116 p. (Rus.)

3. Vuks M.F., Shurupova L.V. Molecular physics and biophysics of the water systems / Zhurnal strukturnoy khymyy. - 1971. - 12, № 4. P. 712 713, P. 730 - 731 (Rus.)

4. Shurchkova Yu.A., Slanik A.V. Description of an experimental vacuum stand for research of processes of instantaneous depressurization in a volume and at the profluvium of liquid // Zbirnyk tez dopovidey VIII vseukrayins'koyi naukovo-praktychnoyi konferentsiyi studentiv, aspirantiv i molodykh vchenykh. - P. 16-17 (Rus.)

5. Yvanytskyy H.K., Shurchkova Yu.A., Tselen' B.Ya., Slanyk A.V. Reduction of power expenses at treatment of discretely-impulsive energy input // Zbornyk tezysov IV Mezhd. Nauch.-Praktych. konferentsyy «Sovremennyiye enerhosberyhayushchiye teplovyiye tekhnolohyy (sushka in termovlazhnostnaya obrabotka materyalov). SETT 2011», - T. 1. - P. 446 - 450 (Rus.) 
6. Dolynskyy A.A., Shurchkova Yu.A., Slanyk $A . V$. Microstructure of dry remain of water at the different ways of her treatment // Prom. teplotekhnyka. - 2009. - T. 31, № 7. - P. 86 - 89 (Rus.)

7. Slanik A.V. Use of mechanisms of discrete-pulse input of energy at treatment of water: dys. na zdobuttya nauk. stepenya kandydata tekhnichnykh nauk: 05.14.06 «Tekhnichna teplofizyka ta promyslova teploenerhetyka»/ A.V. Slanik. - Kyiv, 2010. - 190 p. (Rus.)

8. Dolynskyy A.A., Shurchkova Yu.A. Water is in the condition of treatment of DPIE // / Dopovidi NAN Ukrayiny - 2013. - № 8, - P. 35 - 39 (Rus.) 